\title{
Diagnóstico, manejo y prevención de infecciones en pacientes con cirrosis hepática
}

\author{
ALBERTO FICA C.
}

\section{Diagnosis, management and prevention of infections in cirrhotic patients}

Infections in patients affected with liver cirrhosis are frequent, recurrent and associated to unfavorable outcome. They are facilitated by acquired and progressive defects on the innate immune and reticuloendothelial system that are aggravated by alcohol consumption. Infections in patients with cirrhosis are typically bacterial or viral in origin and have in most cases a stereotyped clinical presentation, although diagnosis may be difficult in some cases. Pneumonia, urinary tract infection, bacteremia and spontaneous bacterial peritonitis explain more than $90 \%$ of the cases. The latter requires a high clinical suspicion and a standardized diagnostic work up. Preventive strategies are important in the management of these patients and include chemoprophylaxis against spontaneous bacterial peritonitis in selected cases, vaccines against pneumococcal and influenza infections, and hepatitis A and B vaccine in susceptible patients. Due to limited seroconversion, active immunization should be applied as earlier as possible, before clinical deterioration ensues.

Key words: cirrhosis, infection, diagnosis, management, prevention, chemoprophylaxis.

Palabras clave: cirrosis; infección; diagnóstico; manejo; prevención; quimioprofilaxis.

\section{Introducción}

Las infecciones en pacientes con cirrosis hepática constituyen una importante causa de descompensación clínica, hospitalización y muerte. Estas infecciones incluyen microorganismos bacterianos o virales, ocasionalmente fúngicos y rara vez parasitarios. A pesar de que el diagnóstico de este tipo de complicaciones no se ha modificado mayormente en los últimos años, se han ido delineando nuevos conocimientos, especialmente en estrategias de prevención, que ameritan una revisión. En ese artículo se analizarán consecutivamente las factores patogénicos que facilitan las complicaciones infecciosas, los microorganismos, y cuadros infecciosos asociados, algunas nociones diagnósticas y terapéuticas y finalmente estrategias preventivas. No se incluye en esta revisión el manejo específico de las infecciones crónicas por el virus $\mathrm{B}$ o $\mathrm{C}$ de la hepatitis. (VHB, VHC).

\section{Factores patogénicos que facilitan infecciones en pacientes con cirrosis hepática}

Los factores patogénicos descritos en estos pacientes son diversos e involucran alteraciones inmunológicas, consumo de alcohol y factores nosocomiales.

\section{Factores inmunológicos}

Las alteraciones inmunológicas descritas son variadas, no son universales y sólo algunas de ellas han podido ser correlacionadas con la severidad de la cirrosis hepática o el pronóstico. (Tabla 1). Las alteraciones mejor caracterizadas corresponden a la deficiente acción bactericida del suero (ABS), opsoninas y complemento, alteraciones funcionales en los neutrófilos y a los cambios en la actividad del sistema retículoendotelial (SRE). En los párrafos siguientes se revisarán estos aspectos en forma separada aunque ellos participan en forma interrelacionada.

Hospital Clínico Universidad de Chile: Departamento de Medicina, Sección de Infectología. Santiago, Chile. 
Actividad bactericida del suero. Esta capacidad está deprimida en pacientes con cirrosis, un fenómeno que parece ser explicado por la hipocomplementemia observada en una fracción de los pacientes y por un déficit de anticuerpos específicos, que impide la activación de la lisis por la vía clásica del complemento ${ }^{1}$. Las concentraciones de lisozima en el suero, otro factor involucrado en la $\mathrm{ABS}$, han resultado normales o incluso aumentadas en estos pacientes y no explican esta deficiencia ${ }^{1}$. A pesar de su hipergamaglobulinemia, paradójicamente estos pacientes tienen una carencia de anticuerpos específicos contra bacterias comunes, que impide su destrucción.

La ABS sólo permite la lisis de bacilos gramnegativos sensibles a este efecto y no tiene actividad sobre bacilos gramnegativos naturalmente resistentes a este fenómeno. En pacientes

Tabla 1. Defectos inmunes descritos en pacientes con cirrosis hepática

\begin{tabular}{|c|c|c|}
\hline Aspecto & Mecanismo & $\begin{array}{l}\text { Implicancias y relación con } \\
\text { morbilidad y pronóstico }\end{array}$ \\
\hline $\begin{array}{l}\text { Actividad bactericida } \\
\text { del suero }\end{array}$ & $\begin{array}{l}\text { Déficit de IgM específicas para } \\
\text { ciertas cepas de BGN susceptibles } \\
\text { a este fenómeno (sólo una fracción } \\
\text { de las bacteriemias). Explicada en } \\
\text { ciertos casos por hipocomplemen- } \\
\text { temia }\end{array}$ & $\begin{array}{l}\text { Favorece bacteriemia por agentes } \\
\text { susceptibles a este fenómeno. } \\
\text { No se ha explorado su importancia en } \\
\text { el pronóstico }\end{array}$ \\
\hline Opsoninas & $\begin{array}{l}\text { Déficit de opsonización en el } \\
\text { suero o en el líquido ascítico en } \\
\text { una fracción de pacientes con falla } \\
\text { hepática o cirrosis hepática. Ligada } \\
\text { a un déficit de complemento en } \\
\text { algunos casos. }\end{array}$ & $\begin{array}{l}\text { Disminuye la capacidad de PMN para } \\
\text { eliminar bacterias y otros patógenos. } \\
\text { Concentraciones similares o inferiores } \\
\text { a } 1 \mathrm{~g} / \mathrm{dL} \text { en el líquido ascítico se asocian } \\
\text { a un déficit de esta propiedad. En pacien- } \\
\text { tes con falla hepática fulminante no ha } \\
\text { podido ser asociada a un pronóstico ad- } \\
\text { verso }\end{array}$ \\
\hline Complemento & $\begin{array}{l}\text { Valores de C3 disminuidos } \\
\text { significativamente en pacientes } \\
\text { con cirrosis descompensada. } \\
\text { Fenómeno secundario a una menor } \\
\text { síntesis y a mayor consumo }\end{array}$ & $\begin{array}{l}\text { Se ha asociado en forma independiente } \\
\text { a infecciones y un pronóstico adverso } \\
\text { junto a la descompensación de la } \\
\text { enfermedad }\end{array}$ \\
\hline Quimiotaxis & $\begin{array}{l}\text { Función deprimida en pacientes } \\
\text { con cirrosis. En parte explicada } \\
\text { por déficit de complemento }\end{array}$ & $\begin{array}{l}\text { Favorece infecciones locales o sistémicas. } \\
\text { No se ha explorado su importancia en } \\
\text { el pronóstico }\end{array}$ \\
\hline $\begin{array}{l}\text { Fagocitosis y efecto } \\
\text { bactericida de los PMN }\end{array}$ & $\begin{array}{l}\text { Funciones deprimidas en dos tercios } \\
\text { de los casos aproximadamente. La } \\
\text { deficiencia en el efecto bactericida } \\
\text { es secundaria a una disminución en } \\
\text { la producción de superóxido y en la } \\
\text { capacidad de degranulación de los } \\
\text { neutrófilos }\end{array}$ & $\begin{array}{l}\text { Podrían favorecer infecciones locales o } \\
\text { sistémicas. No se ha explorado su } \\
\text { importancia en el pronóstico }\end{array}$ \\
\hline Sistema retículo-endotelial & $\begin{array}{l}\text { Función deprimida en pacientes con } \\
\text { cirrosis. Puede ser secundaria a un } \\
\text { defecto en la opsonización, depre- } \\
\text { sión directa del SRE o shunting } \\
\text { porto-sistémico secundario a } \\
\text { alteraciones anatómicas }\end{array}$ & $\begin{array}{l}\text { Favorece bacteriemias. Asociado a un } \\
\text { pronóstico adverso y a una mayor } \\
\text { frecuencia de infecciones }\end{array}$ \\
\hline Lectina tipo $\mathrm{C}$ & $\begin{array}{l}\text { Mutaciones específicas en el gen } \\
\text { estructural (MBL)* han sido descritas } \\
\text { con mayor frecuencia en pacientes } \\
\text { con cirrosis sintomática por VHB, } \\
\text { infecciones asociadas y en pacientes } \\
\text { que fallecen por falla hepática } \\
\text { fulminante }\end{array}$ & $\begin{array}{l}\text { Implicancia en el pronóstico de pobla- } \\
\text { ciones asiáticas afectadas por VHB. } \\
\text { Posibilidad de medir concentraciones } \\
\text { en el suero }\end{array}$ \\
\hline
\end{tabular}

*mannose-binding lectin; BGN: bacilos gramnegativos 
inmunocompetentes, $95 \%$ de las bacteriemias por bacilos gramnegativos están asociadas a agentes resistentes a la ABS. En contraste en pacientes con cirrosis se observan bacteriemias por bacilos gramnegativos resistentes o susceptibles a la $\mathrm{ABS}^{1}$.

Opsonización en suero y líquido ascítico (LA). La opsonización requiere la participación de polimorfonucleares (PMN), complemento y/o anticuerpos. Se determina midiendo in vitro la capacidad de PMN normales, en presencia de diferentes fluidos del paciente, para reducir la carga microbiana de un inóculo bacteriano luego de algunos minutos u horas. Se ha descrito una deficiencia en esta capacidad en el suero de pacientes con falla hepática de diferente etiología, la que es muy frecuente $(>80 \%)$ y afecta a bacterias y levaduras ${ }^{2}$. En comparación a sueros controles, la capacidad de opsonización por el suero en estos pacientes está reducida aproximadamente a un tercio y se recupera en paralelo a la recuperación clínica del paciente. En estos pacientes, este fenómeno se explica por un déficit en diferentes componentes del complemento pero no ha podido ser ligado al pronóstico del paciente. Deficiencias en opsonización también han sido reportadas en pacientes con cirrosis hepática o hepatitis alcohólica, aunque no han podido ser correlacionadas con un déficit en los factores del complemento ${ }^{3}$.

Las deficiencias en la capacidad de opsonización también han sido descritas en el LA de pacientes con cirrosis, pero no en ascitis de otras causas como carcinomatosis, insuficiencia cardíaca o ascitis pancreática. Más aún, valores deficientes de esta propiedad han sido asociados a un déficit de $\mathrm{C} 3$ y C4 en el LA y a un riesgo de presentar peritonitis bacteriana espontánea (PBE) en forma independiente a otras variables ${ }^{4}$. La actividad opsónica está muy relacionada a la concentración total de proteínas en el LA. Cuando la concentración de proteínas es $\leq 1 \mathrm{~g} / \mathrm{dL}$, se puede asumir un déficit de esta función ${ }^{5}$.

Complemento. El sistema del complemento es fundamental en la defensa contra infecciones bacterianas y su participación puede involucrar tres mecanismos diferentes: la muerte celular directa por el complejo de ataque de membrana; el reclutamiento de células fagocíticas hacia los sitios de infección por mediadores de la inflamación; y la generación de opsoninas que contribuyen al reconocimiento inmune de microorganismos ${ }^{6}$. La concentración sérica de $\mathrm{C} 3$ y $\mathrm{C} 4$ se encuentra disminuida en pacientes con cirrosis hepática descompensada, al igual que la actividad hemolítica del complemento por vía alterna ${ }^{6}$. Esta disminución está relacionada con otros parámetros de la función hepática. La concentración disminuida de $\mathrm{C} 3$ se explica por una síntesis disminuida y un aumento del consumo de $\mathrm{C} 3$, el que probablemente obedece a la circulación habitual de endotoxinas en la sangre de estos pacientes. Las bajas concentraciones de $\mathrm{C} 3$ en el suero se han asociado significativamente a una mayor frecuencia de infecciones y a mayor mortalidad, en forma independiente a otras variables ${ }^{6}$. La deficiencia adquirida de $\mathrm{C} 3$ en pacientes con cirrosis hepática podría explicar un mayor riesgo de infecciones a través de un déficit en la capacidad de opsonización, aunque este parámetro no aparece alterado en forma consistente en todos los pacientes ${ }^{2,6}$.

Alteraciones funcionales en los neutrófilos. En un porcentaje de pacientes con cirrosis hepática se observan defectos en la capacidad de fagocitar y de ejercer un efecto bactericida sobre bacilos gramnegativos o cocáceas grampositivas en pruebas in vitro ${ }^{7}$. Este defecto en la capacidad bactericida ocurre antes de los eventos infecciosos y parece ser explicado por una disminución en la síntesis de superóxido por los PMN, y una menor capacidad de degranulación y menor contenido intracelular de lizosima y mieloperoxidasa en estas células?

Se han descrito deficiencias en la capacidad de migración de los neutrófilos, las que han resultado proporcionales a la severidad de la enfermedad hepática. Sin embargo, se desconoce si estos resultados están meramente relacionados a una menor concentración plasmática de complemento u obedecen a una genuina disfunción de los neutrófilos ${ }^{8}$.

Sistema retículo-endotelial. Este sistema participa en la remoción de microorganismos circulantes en la sangre y constituye un factor de defensa importante contra las infecciones, especialmente las bacteriemias ${ }^{9}$. El SRE se concentra principalmente en el hígado, involucra a las células de Küpffer y otras células sinusoidales y su actividad está deprimida en pacientes con cirrosis hepática, aunque en esta última condición existe una actividad compensatoria esplénica y en la médula ósea9 ${ }^{9}$.

La actividad del SRE se ha evaluado mediante la depuración de tecnecio sulfurocoloide, más de la mitad de los pacientes con cirrosis hepática demuestra una actividad disminuida de este sistema9 . Más aún, esta disminución se ha asociado a una mayor frecuencia de bacteriemia durante la hospitalización o seguimiento de estos pacientes y a una mayor mortalidad ${ }^{9}$. La menor actividad de este sistema no es predecible por los paráme- 
tros habituales de función hepática. La menor actividad del SRE predispone a la entrada de bacterias al torrente sistémico desde el sistema portal y podría ser explicada por un déficit de opsoninas, shunting porto-sistémico o depresión de la función fagocítica del SRE.

Otros factores inmunes. Otro componente de la inmunidad innata, la lectina de tipo C (mannosebinding lectin), una proteína de fase aguda con analogía estructural a $\mathrm{C} 1$, que puede opsonizar y activar el sistema del complemento contra bacterias, virus, parásitos u hongos, puede participar en la propensión a las infecciones observadas en pacientes con cirrosis o falla hepática ${ }^{10,11}$. Mutaciones en los genes estructurales o regulatorios de esta proteína han sido asociadas a infecciones graves por Streptococcus pneumoniae, Neisseria menigitidis o en pacientes post-quimioterapia y a infecciones bacterianas recurrentes en adultos y niños ${ }^{10,12}$.

Mutaciones específicas en el gen estructural de esta proteína han sido ligadas además, a la progresión de la enfermedad hepática por VHB o VHC, desde formas asintomáticas hacia formas clínicas en la población asiática ${ }^{11,13}$. En este grupo de pacientes, los que desarrollan peritonitis bacteriana espontánea (PBE) portan con mayor frecuencia mutaciones en el gen MBL (64\%) que aquellos que evidencian otras formas clínicas de la enfermedad por VHB. Esta misma mutación (codón 54 del gen MBL) también ha sido ligada a un pronóstico adverso en pacientes con falla hepática fulminante (FHF) por infección por VHB al igual que concentraciones disminuidas de $\mathrm{MBL}$ en el suero durante un episodio de $\mathrm{FHF}^{14}$ (Tabla 1).

\section{Consumo de alcohol}

El alcohol puede ejercer un efecto deletéreo mediante una depresión neurológica, favoreciendo neumonías aspirativas, descompensaciones de la enfermedad de base mediante hepatitis alcohólica o por alteraciones en el sistema inmune.

En pacientes con consumo crónico de alcohol se produce una neutropenia, usualmente leve y reversible con la abstinencia. Este fenómeno es provocado por una depresión medular; la liberación de PMN desde la médula ósea no está afectada $a^{15}$. La ingestión crónica de alcohol afecta la quimiotaxis de los PMN hacia los sitios de inflamación; sin embargo, la fagocitosis y muerte intracelular de bacterias no se afectan directamente por el alcohol ${ }^{15}$.

La respuesta inmune celular también es afectada por el consumo de alcohol. Las pruebas de hipersensibilidad retardada están deprimidas en pacientes con hepatitis alcohólica y el consumo de este compuesto puede provocar linfopenia, especialmente si se asocia a hepatitis alcohólica ${ }^{15}$. El alcohol disminuye también la capacidad de transformación blástica y citotoxicidad de las células natural killer (específicamente en pacientes con cirrosis y desnutrición). En pacientes con cirrosis establecida, las infecciones son más frecuentes en pacientes que consumen alcohol en comparación a otras causas de cirrosis ${ }^{16}$.

\section{Factores nosocomiales}

Los pacientes con cirrosis están expuestos a la disrupción de las barreras naturales de defensa, como por ejemplo ante procedimientos invasores durante la hospitalización (vía venosa central, catéter urinario o intubación endotraqueal) o ante la disminución del mecanismo reflejo de la tos y el riesgo de aspiración en pacientes con encefalopatía hepática o intoxicación alcohóli$\mathrm{ca}^{17}$.

Las alteraciones inmunológicas en pacientes con cirrosis representan una deficiencia en la inmunidad innata humoral y en el SRE, que explican infecciones bacterianas recurrentes. Sobre este panorama se agregan procedimientos invasores que facilitan infecciones nosocomiales y el efecto deletéreo del alcohol que favorece descompensaciones de la enfermedad, eventos de aspiración y alteraciones inmunológicas sobreagregadas. Las infecciones en pacientes cirróticos no se asocian a microorganismos oportunistas propios de pacientes inmunocomprometidos.

\section{Microorganismos y cuadros infecciosos habituales}

Las infecciones en pacientes cirróticos incluyen cuatro tipos de infecciones características: PBE ( 44\%), infección urinaria ( 25\%), neumonía $(\sim 15 \%)$ y bacteriemias sin foco $(\sim 5 \%)^{18}$. Estas infecciones explican más del $90 \%$ de los casos. En algunos pacientes el diagnóstico de estas condiciones puede ser difícil.

Peritonitis bacteriana espontánea. Corresponde a la infección bacteriana más frecuente en pacientes con cirrosis hepática y puede presentarse como insuficiencia hepática, fiebre, signos abdominales o como un cuadro asintomático. Debe ser sospechada en todo paciente que se presenta con cirrosis descompensada y ascitis. ${ }^{19}$ Este cuadro se asocia a una mortalidad aproximada de $40 \%$ a los 6 meses del evento inicial y tiene $40 \%$ de recurrencia en los 6 a 12 meses siguientes. Los factores de riesgo para esta condición, identificados en estudios prospectivos (análisis multivariado), incluyen una concentra- 
ción de proteínas totales en el $\mathrm{LA} \leq 1 \mathrm{~g} / \mathrm{dL}$, hiperbilirrubinemia $(>2,5 \mathrm{mg} / \mathrm{dL})$, hemorragia gastrointestinal reciente, antecedentes de otra $\mathrm{PBE}$, procedimientos invasores y falla hepática fulminante ${ }^{5,17}$.

Los criterios diagnósticos de PBE se presentan en la Tabla 2 junto a los de una condición similar: la ascitis neutrocítica con cultivo negativo. Ambas se enfrentan de igual manera y requieren que se haya descartado causas secundarias de infección. Un recuento de $250 \mathrm{PMN} / \mathrm{mm}^{3}$ representa un corte de alta sensibilidad para pesquisar todos los casos de infección, aunque su especificidad no es óptima ${ }^{20}$. Ello permite aplicar el beneficio de la terapia hacia todos los pacientes afectados con PBE.

Los casos con cultivo positivo del líquido ascítico pero sin respuesta inflamatoria (bacterioascitis no neutrocítica) representan una condición heterogénea que en algunos casos indica la colonización secundaria de la ascitis desde un foco extraperitoneal de infección, asociándose habitualmente a signos locales o sistémicos de inflamación. Otros casos obedecen a una colonización espontánea, la que es generalmente asintomática. El curso de la bacterioascitis no tratada es variable, pudiendo progresar a PBE, especialmente en aquellos casos asociados a síntomas locales o sistémicos, o ser autolimitada. Un consenso de expertos ha opinado recientemente que el término bacterioascitis debe ser reservado exclusivamente a aquellos pacientes sin síntomas locales o sistémicos de infección ${ }^{20}$ (Tabla 2). La laparocentesis debe ser repetida en todos los casos de bacterioascitis para descartar una progresión a $\mathrm{PBE}^{20}$.

Más de $40 \%$ de los casos de PBE se asocian a bacteriemia y los hemocultivos deben ser solicitados de rigor cada vez que se sospecha esta condición.

La laparocentesis diagnóstica está indicada en todos aquellos pacientes que se hospitalizan con ascitis; cada vez que el paciente desarrolla signos de peritonitis, signos sistémicos de infección, encefalopatía hepática con o sin factores de descompensación o deterioro de la función renal sin causa aparente; y antes de iniciar profilaxis antimicrobiana en pacientes con ascitis y hemorragia digestiva ${ }^{20}$.

Los microorganismos más frecuentemente asociados a PBE corresponden a bacilos gramnegativos o cocáceas grampositivas. Series nacionales dan cuenta del predominio de Escherichia coli, Klebsiella pneumoniae y S. pneumoniae o Streptococcus del grupo viridans. Aproximadamente dos tercios de los casos se asocian a bacilos gramnegativos ${ }^{5,18,19}$. Ocasionalmente la PBE puede ser ocasionada por Listeria monocytogenes, un bacilo grampositivo ${ }^{21,22}$. La PBE es una condición monomicrobiana. En los últimos años han emergido bacilos gramnegativos resistentes a quinolonas y se ha incrementado la participación relativa de cocáceas grampositivas, debido a la práctica rutinaria de la quimioprofilaxis con estos compuestos en pacientes en riesgo (ver más adelante). En otras latitudes, cerca de $50 \%$ de los aislados de bacilos gramnegativos de pacientes con PBE en quimioprofilaxis con estos compuestos pueden ser ahora resistentes a quinolonas ${ }^{23}$.

Infección urinaria. Esta complicación se presenta en forma frecuente en estos pacientes, predispone a episodios de bacteriemia, puede ser asintomática y estar asociada al uso de catéteres urinarios. Los microorganismos asociados no difieren de otras poblaciones, predominando los bacilos gramnegativos ${ }^{17}$. Esta infección se observa con mayor frecuencia en mujeres y en pacientes con cirrosis biliar primaria la incidencia de bacteriuria es mayor en comparación a otras causas de daño hepático crónico (19 versus $7 \%)^{24}$.

Neumonías. Los pacientes con cirrosis están expuestos al riesgo de neumonía debido a las alteraciones inmunitarias ya descritas, al com-

Tabla 2. Criterios diagnósticos de PBE, ascitis neutrocítica con cultivo negativo y bacterioascitis

\begin{tabular}{ll}
\hline Condición & Criterios diagnósticos \\
\hline - Peritonitis bacteriana espontánea & $\begin{array}{l}\text { Presencia de cultivo positivo en el LA, sin causas secun- } \\
\text { darias de infección y con al menos } 250 \mathrm{PMN} / \mathrm{mm}^{3}\end{array}$ \\
- Ascitis neutrocítica con cultivo negativo & $\begin{array}{l}\text { Presencia de al menos } 250 \mathrm{PMN} / \mathrm{mm}^{3} \text { con cultivo negati- } \\
\text { vo en el LA, sin causas secundarias de infección }\end{array}$ \\
- Bacterioascitis & $\begin{array}{l}\text { Recuento inferior a } 250 \mathrm{PMN} / \mathrm{mm}^{3}, \text { cultivo positivo en } \\
\text { el LA y ausencia de signos locales o sistémicos de infec- } \\
\text { ción }\end{array}$ \\
\hline
\end{tabular}


promiso de conciencia o leucopenia secundarios a su enfermedad de base o al consumo de alcohol, y a ciertas exposiciones comunitarias específicas como la tuberculosis o influenza. El agente etiológico más frecuente es $S$. pneumoniae, a los que se agregan bacilos gramnegativos entéricos o respiratorios como E. coli, K. pneumoniae y Haemophilus influenzae, respectivamente. Las infecciones por microorganismos anaerobios son secundarias en estos pacientes habitualmente a eventos de aspiración y dentadura en mal estado. Los cuadros de neumonía pueden ser graves o complicarse con mayor frecuencia con abscesos, cavitaciones o empiema pleural ${ }^{17}$.

Bacteriemia. Las bacteriemias en pacientes con cirrosis pueden presentarse sin un foco de origen o estar asociadas a neumonía, PBE, infecciones urinarias o catéteres vasculares. Los agentes etiológicos reflejan esta lista de condiciones asociadas, predominando los bacilos gramnegativos y cocáceas grampositivas. S. pneumoniae es un importante agente de bacteriemia en pacientes alcohólicos y cirróticos ${ }^{25}$.

Otras infecciones. Una diversidad de otras infecciones puede ser observada en pacientes con cirrosis hepática. Estas incluyen tuberculo$\operatorname{sis}^{26}$, meningitis causada por $S$. pneumoniae o $L$. monocytogenes ${ }^{21}$; fascitis necrosante y sepsis por Vibrio vulnificus o $V$. parahaemolyticus en personas que consumen moluscos crudos o están en contacto con estuarios marinos ${ }^{27}$; diarrea por Salmonella enteritidis ${ }^{28}$; difteria cutánea o respiratoria $^{29}$ y endocarditis por agentes inhabituales como Bartonella quintana ${ }^{30}$.

\section{Aspectos diagnósticos}

Peritonitis bacteriana espontánea. Se define bajo esta condición una infección del LA en la cual se ha comprobado el crecimiento de bacte- rias, hay un recuento de $\mathrm{PMN} \geq 250 / \mathrm{mm}^{3}$ y se ha descartado una fuente intraabdominal de infección $^{31}$. La sospecha de PBE se debe plantear frente a un paciente con cirrosis hepática que presenta dolor abdominal, fiebre, encefalopatía hepática, insuficiencia renal o sensibilidad abdominal.

Los cuadros de PBE se deben diferenciar de aquellos secundarios a perforación gastrointestinal en un paciente con cirrosis, aunque esta última condición es infrecuente. Los síntomas y signos son comunes a ambas condiciones y no permiten su reconocimiento ${ }^{32}$. El recuento celular de leucocitos y PMN no permite distinguir entre ambas, debido a la existencia de recuentos elevados en las dos. Los casos de perforación gastrointestinal se han asociado a un líquido que simultáneamente presenta un alto contenido de proteínas y LDH, bajos valores de glucosa y cultivos polimicrobianos que contrastan con los hallazgos propios de la $\mathrm{PBE}^{32}$. Un consenso de especialistas ha propuesto que se debe plantear la sospecha de peritonitis secundaria a una perforación intestinal cuando se cumple alguno de los siguientes tres criterios: falta de respuesta a la terapia antimicrobiana (no descenso de PMN); cultivo polimicrobiano, especialmente con anaerobios o levaduras; o al menos dos de los siguientes hallazgos en el líquido ascítico: glucosa $<50 \mathrm{mg} / \mathrm{dL}$, concentración de proteínas $>10 \mathrm{~g} / \mathrm{L}$, concentración de LDH superior a la concentración de LDH en suero $^{20}$ (Tabla 3).

El cultivo de LA debe efectuarse en frascos de hemocultivos inoculados al lado de la cama del paciente $^{31}$. Esta estrategia permite incrementar el rendimiento diagnóstico de 43 a 93\% en comparación a una muestra de $2 \mathrm{ml}$ de LA enviada a cultivo convencional al laboratorio. Además acelera el crecimiento de las bacterias permitiendo

Tabla 3. Parámetros diagnósticos asociados a PBE y criterios de sospecha de peritonitis secundaria a perforación gastrointestinal

Peritonitis bacteriana espontánea

- Concentración de proteínas habitualmente $<1 \mathrm{~g} / \mathrm{dL}$

- Valores discretamente elevados de LDH

- Concentraciones normales o discretamente elevadas de glucosa

- Cultivo monomicrobiano. Sólo $12 \%$ se presenta con cultivo polimicrobiano

Criterios de sospecha de peritonitis secundaria a perforación (uno de tres)

- Falta de respuesta al tratamiento antimicrobiano (no descenso en recuento de PMN)

- Cultivo polimicrobiano, especialmente con anaerobios o levaduras

- Al menos dos de los siguientes hallazgos en el líquido ascítico: Glucosa $<50 \mathrm{mg} / \mathrm{dL}$

Concentración de proteínas $>1 \mathrm{~g} / \mathrm{dL}$

LDH en LA > LDH suero 
que casi la totalidad de los cultivos positivos sean detectados antes de 24 horas de incubación ${ }^{31}$. El volumen óptimo de muestra corresponde a 10 a $20 \mathrm{ml}$ por frasco de hemocultivo. La tinción de Gram tiene una muy baja sensibilidad aunque se centrifugue la muestra $(\leq 10 \%)$.

Aproximadamente $40 \%$ de los casos de PBE presentan bacteriemia asociada y por ello se debe cultivar la sangre en todos los casos bajo sospecha. Los hemocultivos permiten además reconocer una fracción de las etiologías de neumonía o infecciones urinarias y los casos de bacteriemia sin foco, patologías frecuentes en pacientes cirróticos.

\section{Aspectos terapéuticos}

Peritonitis bacteriana espontánea. El tratamiento de la PBE debe ser iniciado en forma empírica cada vez que se identifique un recuento de PMN superior a 250 células $/ \mathrm{mm}^{3}$. Para tratar esta complicación se han utilizado diferentes esquemas terapéuticos con actividad sobre los microorganismos involucrados. Hasta ahora no se ha demostrado una superioridad terapéutica de cefalosporinas de tercera generación sobre otras alternativas tales como quinolonas en su impacto sobre la mortalidad o la resolución de los síntomas. De la misma manera, la dosis y duración de cefotaxima por vía endovenosa, un compuesto comúnmente usado, no ha sido definida con claridad, encontrándose equivalencia terapéutica entre 4 versus 8 gramos diarios y entre 5 y 10 días de terapia ${ }^{33}$. Tampoco han sido establecidas las ventajas de la terapia oral sobre la terapia parenteral, debido en parte al número reducido de pacientes tratados en diferentes ensayos. Los esquemas con ceftriaxona han utilizado 2 gramos diarios en una o dos dosis. En la Tabla 4 se presentan algunos esquemas de uso frecuente. Las quinolonas están indicadas como opción de primera línea cuando hay alergia a cefalosporinas y cuando el paciente no ha recibido profilaxis de PBE con estos compuestos. Adicionalmente, cuando el estudio de susceptibilidad in vitro así lo determina. La laparocentesis debe ser repetida 48 a 72 horas luego de iniciado el tratamiento para confirmar un descenso del recuento de PMN. La falta de respuesta sugiere un espectro antimicrobiano insuficiente o una causa secundaria de peritonitis ${ }^{20}$.

Manejo de otras condiciones. El tratamiento de infecciones urinarias, neumonías y bacteriemias no difiere en estos pacientes respecto a las recomendaciones para otros pacientes. Sin embargo, al menos tres precauciones deben ser consideradas: el uso de aminoglucósidos aumenta el riesgo de nefrotoxicidad en pacientes con cirrosis y por ello no se recomienda su indicación; cefoperazona o derivados (cefoperazona/ sulbactam) están asociados a un mayor riesgo de hemorragia o hipoprotrombinemia, en comparación a otras cefalosporinas de uso común en Chile y su efecto no puede ser revertido o prevenido en pacientes con cirrosis; diversos compuestos antimicrobianos inducen cambios sobre el metabolismo de otros fármacos y estas interacciones deben ser consideradas en el tratamiento (p. ej.: macrólidos, triazoles).

\section{Prevención}

Las estrategias preventivas en estos pacientes incluyen la abstinencia en el consumo de alcohol, la prevención de infecciones virales o bacterianas específicas mediante vacunas y la quimioprofilaxis de PBE.

\section{Prevención mediante vacunas}

Al menos cuatro vacunas pueden ser consideradas en pacientes con cirrosis: anti-neumocóccica,

Tabla 4. Esquemas de tratamiento de PBE

$\beta$-lactámicos

- Amoxicilina (1 g)-ác. clavulánico (0,2 g): un frasco c/8 h ev más 500/125mg oral c/8 h

Cefalosporinas

- Cefotaxima: $2 \mathrm{~g} / 12 \mathrm{~h} \mathrm{ev} ; 2 \mathrm{~g} / 8 \mathrm{~h}$ ev o $2 \mathrm{~g} / 6 \mathrm{~h}$ ev

- Ceftriaxona: 2 gramos/día ev en una o dos dosis

- Cefixima: $400 \mathrm{mg} /$ día oral

Quinolonas

- Ciprofloxacina: $200 \mathrm{mg} / 12 \mathrm{~h}$ ev o $500 \mathrm{mg} / 12 \mathrm{~h}$ oral*

- Ofloxacina: $400 \mathrm{mg} / 12 \mathrm{~h}$ día oral (equivalente a $500 \mathrm{mg} / 12 \mathrm{~h}$ de levofloxacina) 
anti-FLU y las de VHA y VHB en pacientes susceptibles. Aunque la eficacia de estas vacunas es todavía incierta en esta población, se recomienda su uso por las ventajas potenciales en la prevención de enfermedades graves, tener efectos adversos mínimos y la evidencia de una inmunogenicidad aceptable en la mayor parte de los pacientes.

Vacuna anti-neumocóccica. Es ampliamente recomendada en pacientes con cirrosis hepática debido a la frecuencia y a las devastadoras consecuencias de la infección por $S$. pneumoniae. Sin embargo, la evidencia de su eficacia protectora es indirecta. Mayoritariamente se utiliza la vacuna de polisacáridos capsulares 23-valente que incluye el $99 \%$ de los serotipos circulantes en nuestro medio. La inmunogenicidad de las vacunas polivalentes se ha evaluado en diferentes ensayos y con distintos grados de enfermedad hepática (Child-Pugh A, B y C) apreciándose su buena tolerancia local y sistémica ${ }^{34}$. La respuesta de tipo IgG, IgM e IgA es significativa en todos los pacientes con cirrosis hepática, puede ser similar o inferior a sujetos controles y tiende a desaparecer a los 6 meses, aunque permanece sobre niveles preinmunización ${ }^{34,35}$. Los anticuerpos generados por la vacuna son funcionales y tienen actividad opsonizante ${ }^{36}$. La declinación de anticuerpos en el tiempo se acelera en caso de trasplante hepático ${ }^{34}$.

Se desconoce hasta ahora, cuál sería la mejor estrategia para mejorar la limitada inmunogenicidad de la vacuna de polisacáridos capsulares en pacientes con cirrosis hepática. Las revacunaciones con productos polivalentes tradicionales no parecen asegurar una mejor respuesta o memoria inmunológica en la población mayor ${ }^{37}$. Teóricamente, las vacunas anti-neumocóccicas conjugadas con proteínas podrían mejorar la inmunogenicidad y memoria inmunológica, tal como ha sido observado en la población infantil. Sin embargo, hasta ahora ello no ha sido explorado en pacientes con cirrosis y la experiencia en adultos mayores no ha sido satisfactoria ${ }^{34,37}$.

Como se mencionó, a pesar de la incertidumbre que rodea la eficacia de la vacuna antineumocóccica, su uso es recomendado ampliamente por sus potenciales beneficios, buena tolerancia y facilidad de administración.

Influenza. La infección por el virus FLU es capaz de descompensar a los pacientes con cirrosis, induciendo insuficiencia hepática o facilitando sobreinfecciones bacterianas ${ }^{38,39}$. Hasta ahora han sido escasos los estudios de inmunogenicidad con vacuna FLU trivalente y ellos han incluido un reducido número de pacientes. $\mathrm{La}$ evidencia indica que para pacientes con cirrosis por VHB o VHC en etapas Child-Pugh B/C, la vacuna permite títulos protectores (títulos de inhibición de hemaglutinación $\geq 1 / 40$ ) en $100 \%$ de los pacientes al mes de inmunización, para todos sus antígenos ${ }^{40}$. La vacuna es bien tolerada en estos pacientes y no induce cambios en las pruebas de función hepática hasta un mes de seguimiento. Se desconoce el perfil de respuesta en pacientes con cirrosis de etiología alcohólica.

Vacunas contra VHB y VHA. Aunque ocasional, la sobreinfección por VHA o VHB en pacientes con cirrosis puede conducir a una descompensación grave, incrementando el riesgo de muerte, y por ello debe considerarse la inmunización protectora en pacientes susceptibles a estos agentes. La infección por VHA en pacientes con daño hepático crónico aumenta 23 a 58 veces la tasa de letalidad, en comparación a aquellos sin enfermedad de base ${ }^{41}$.

Los pacientes con cirrosis e insuficiencia hepática (Child-Pugh B o C) tienen una capacidad de respuesta serológica reducida con la vacuna para el VHA. Sólo 50\% de los pacientes fueron capaces de adquirir títulos protectores de anticuerpos $(\geq 33 \mathrm{mUI} / \mathrm{mL})$ ante un esquema estándar de vacuna de dos dosis separadas por dos meses $(1.440 \text { U ELISA por dosis })^{42}$. No obstante, la vacuna anti VHA es bien tolerada en estos pacientes y no genera descompensaciones clínicas o bioquímicas de la enfermedad. En países desarrollados, más de $50 \%$ de los pacientes adultos con cirrosis hepática son susceptibles para esta infección, una cifra superior a la observada en nuestro medio donde una baja fracción de la población $(<30 \%)$ permanece susceptible después de los 15 años de edad ${ }^{43}$. Los pacientes con cirrosis descompensada (Child-Pugh B o C) tienen una tasa de respuesta significativamente inferior en comparación a pacientes no descompensados portadores de hepatitis crónica o cirrosis Child-Pugh clase A $(65,7 \text { versus } 98 \%)^{44}$. En un análisis multivariado se identificó al estadio de la cirrosis hepática como el único factor predictor de respuesta serológica para la vacuna VHA en pacientes con cirrosis (73\% para enfermedad compensada, 20,8\% para clase Child-Pugh B y $6,3 \%$ para clase $\mathrm{C})^{44}$. La respuesta serológica en pacientes con hepatitis crónica de diferente etiología (virales y otras causas) es superior para esta vacuna, permitiendo tasas de seroconversión superiores a $90 \%$ luego de dos dosis estándares espaciadas por 6 meses $^{45}$.

Estudios con vacuna anti VHB en pacientes con hepatitis crónica por el VHC, aunque sin 
cirrosis, han demostrado una tasa de seroconversión mayor al $80 \%$ y títulos adecuados de anticuerpos anti $\mathrm{HBsAg}(>100 \mathrm{mUI} / \mathrm{mL}$ en $65 \%)$ similares a grupos controles, al utilizar esquemas tradicionales de inmunización $(0,1$ y 6 meses) con dosis estándar de vacuna $(20 \mu \mathrm{g} / \text { dosis })^{46}$. La vacuna no induce descompensaciones de la enfermedad hepática de base o replicación viral y es bien tolerada en este grupo de pacientes ${ }^{46}$. Tampoco se observa un incremento en los valores plasmáticos basales elevados de FNT- $\alpha$ con la vacuna. La tasa de seroconversión en pacientes con cirrosis es inferior y no supera el 16 ó 37\% según se utilice una dosis estándar o una doble dosis en el esquema ${ }^{47}$.

Inmunización precoz y adherencia a las recomendaciones. Los antecedentes presentados dan cuenta de la importancia de comenzar en forma precoz con un programa de inmunización activa cada vez que se pesquisa un paciente con cirrosis hepática o hepatitis crónica. Lamentablemente la adherencia hacia estas recomendaciones es pobre, disminuyendo su ya reducida eficacia en algunos casos. Un estudio reciente indica que sólo $55 \%$ de los pacientes con cirrosis recibe oportunamente inmunización contra FLU, 34\% contra S. pneumoniae y $26 \%$ contra VHB o $\mathrm{VHA}^{48}$. En la Tabla 5 se resumen las estrategias de inmunización activa en pacientes con cirrosis hepática o hepatitis crónica.

\section{Quimioprofilaxis de PBE}

La PBE es una complicación frecuente y recurrente en pacientes cirróticos. Diversos estudios han logrado demostrar la utilidad de diferentes esquemas profilácticos antimicrobianos para prolongar la sobrevida del paciente, disminuir el riesgo de ocurrencia de PBE y otras infecciones ${ }^{49-51}$. La quimioprofilaxis en pacientes con cirrosis está indicada en tres grupos de pacientes: aquellos con ascitis con una baja concentración de proteínas en el LA o asociadas a hiperbilirrubinemia $>2,5 \mathrm{mg} / \mathrm{dL}$, pacientes con cirrosis que presentan hemorragia gastrointestinal de cualquier causa, aunque no presenten ascitis, y aquellos pacientes que ya han experimentado un episodio de $\mathrm{PBE}^{20}$ (Tabla 6).

El impacto de la quimioprofilaxis sobre la prevención de PBE y otras condiciones en pacientes con cirrosis y hemorragia intestinal se presenta en la Figura 1. La reducción de riesgo es de aproximadamente $32 \%$ para cualquier tipo de infecciones, de $18 \%$ para PBE o bacteriemias, de $7 \%$ para PBE y de $9 \%$ en el riesgo de muerte, en comparación a aquellos pacientes que no reciben profilaxis, según un meta-análisis que logró identificar 5 trabajos randomizados apropiados ${ }^{49}$. El beneficio de la profilaxis es mayor en pacientes con etapas avanzadas de enfermedad. Un metaanálisis reciente, con un mayor número de trabajos $(n=8)$, reprodujo estos hallazgos ${ }^{52}$.

Las posibles indicaciones y esquemas se señalan en la Tabla 6. Las quinolonas han sido los compuestos más evaluados y constituyen una alternativa apropiada para nuestro medio, aunque la emergencia de resistencia en $S$. pneumoniae y bacilos gramnegativos podría limitar su utilidad en un futuro cercano ${ }^{23}$. En ausencia de hemorragia digestiva, las quinolonas pueden ser utilizadas en forma intermitente, con una dosis semanal. Diferentes compuestos antimicrobianos aparecen equivalentes en meta-análisis sobre su impacto para reducir la mortalidad y la morbilidad por diferentes infecciones (Tabla 6). Los esquemas profilácticos pueden iniciarse antes o después de una endoscopia digestiva. A pesar de que existen ensayos que demuestran un efecto beneficioso de cotrimoxazol ${ }^{51}$ no se puede extrapolar su utilización debido a la alta resistencia antimicrobiana a este compuesto en nuestro ambiente.

Tabla 5. Vacunas recomendadas en pacientes con cirrosis hepática o hepatitis crónica

\begin{tabular}{ll}
\hline Vacuna & Dosis y esquema \\
\hline - Influenza & $\begin{array}{l}\text { Dosis anual con vacuna trivalente. Una dosis por vía i.m. en el } \\
\text { mes de abril de cada año. Varios proveedores disponibles en Chile }\end{array}$ \\
- Anti-neumocóccica & $\begin{array}{l}\text { Una dosis i.m. cada } 5 \text { años. Se recomienda la vacuna PS 23- } \\
\text { valente }\end{array}$ \\
- Virus B de la hepatitis(en susceptibles) & $\begin{array}{l}\text { Esquema común de } 3 \text { dosis (0,1 y } 6 \text { meses) por vía i.m. con } 20 \text { o } \\
40 \mu \mathrm{g} / \text { dosis }\end{array}$ \\
- Virus A de la hepatitis(en susceptibles) & Esquema común de 2 dosis $(0$ y 6 meses) por vía i.m. \\
\hline
\end{tabular}

Nota: la vía i.m. no se ha asociado a efectos adversos hemorrágicos en numerosos ensayos 
Tabla 6. Esquemas profilácticos de PBE en pacientes con cirrosis, con o sin hemorragia gastrointestinal

\begin{tabular}{|c|c|c|}
\hline Condición & Criterios de inclusión & Esquemas \\
\hline - Ascitis & $\begin{array}{l}\text { Cirrosis hepática de cualquier causa, } \\
\text { con una concentración de proteína } \\
\leq 1,5 \mathrm{~g} / \mathrm{dL} \text { en líquido ascítico o } \\
\text { hiperbilirrubinemia }>2,5 \mathrm{mg} / \mathrm{dL}\end{array}$ & $\begin{array}{l}\text { Ciprofloxacina } 750 \mathrm{mg} \text { oral a la } \\
\text { semana }\end{array}$ \\
\hline - Episodio previo de $\mathrm{PBE}$ & Ascitis & Idem al anterior \\
\hline $\begin{array}{l}\text { - Cirrosis y hemorragia } \\
\text { gastrointestinal }\end{array}$ & $\begin{array}{l}\text { Cirrosis de cualquier causa y en } \\
\text { etapas Child-Pugh A-C }\end{array}$ & $\begin{array}{l}\text { Norfloxacina } 400 \mathrm{mg} \mathrm{c} / 12 \mathrm{~h} \text { oral por } \\
7 \text { días } \\
\text { Ciprofloxacina } 500 \mathrm{mg} \mathrm{c} / 12 \mathrm{~h} \text { oral por } \\
7 \text { días }\end{array}$ \\
\hline $\begin{array}{l}\text { - Ascitis (con o sin hemorragia) } \\
\text { en pacientes con imposibilidad } \\
\text { de utilizar vía oral o SNG/SNY }\end{array}$ & Idem a los anteriores & $\begin{array}{l}\text { Ciprofloxacina } 200 \mathrm{mg} \mathrm{ev} \mathrm{c/12h} \mathrm{o} \\
\text { levofloxacina } 500 \mathrm{mg} \text { ev/día hasta } \\
7 \text { días }\end{array}$ \\
\hline
\end{tabular}

PBE: peritonitis bacteriana espontánea; SNG: sonda nasogástrica; SNY: sonda nasoyeyunal.

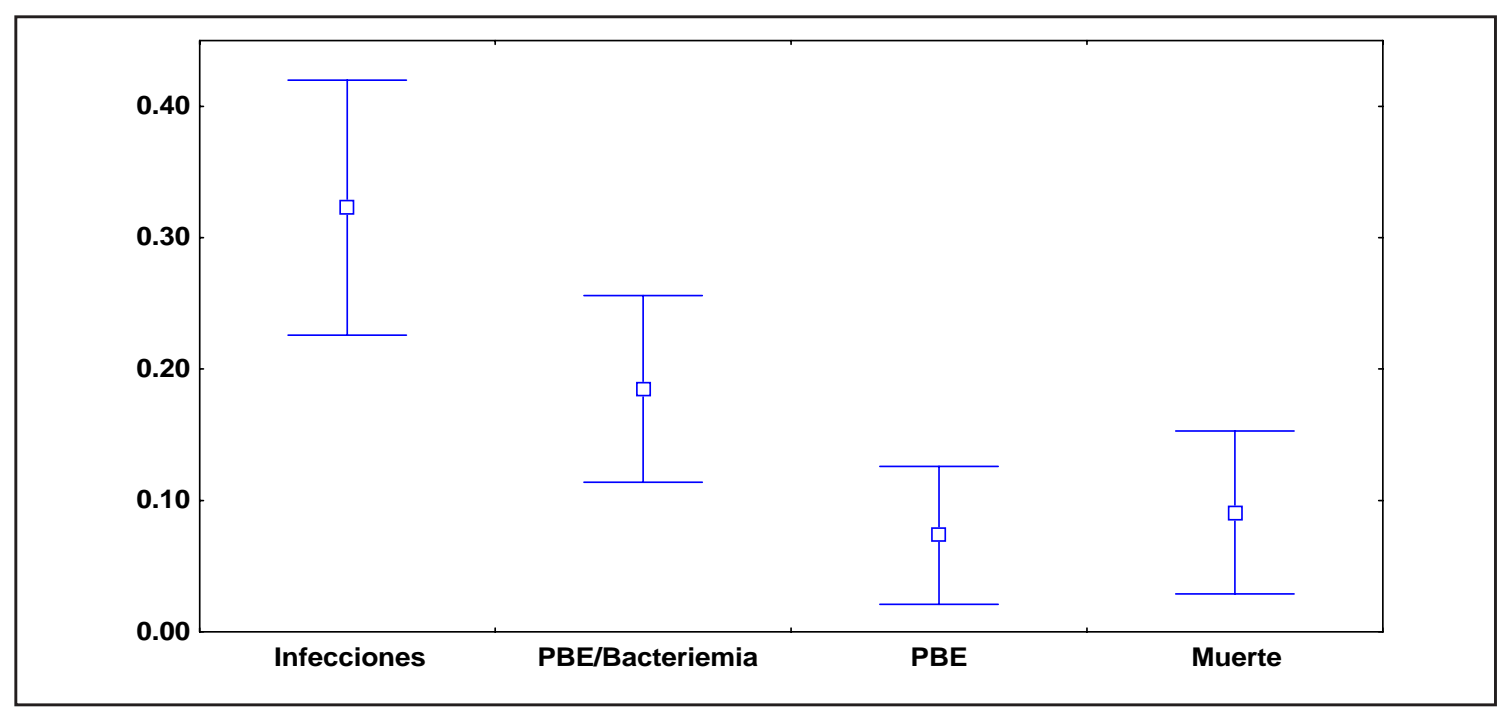

Figura 1. Reducción del riesgo para diferentes eventos infecciosos con quimioprofilaxis ante hemorragia intestinal en pacientes con cirrosis hepática (Adaptado de ref. 49).

La prevención de una PBE contempla además un adecuado manejo de la ascitis con diuréticos, debido a su potencial efecto de incrementar la concentración de proteínas en el LA, la capacidad opsónica local y la concentración del complemento sérico en comparación a una laparocentesis evacuadora ${ }^{53}$.

\section{Conclusiones}

Las infecciones en pacientes con cirrosis hepática son frecuentes, recurrentes y están asociadas a un pronóstico desfavorable. Son facilitadas por una deficiencia adquirida y progresiva de la inmunidad innata humoral, alteraciones en el SRE y en ocasiones el consumo de alcohol.

Las infecciones más frecuentes en pacientes con cirrosis hepática incluyen neumonías, bacteriemias, infecciones urinarias y cuadros de PBE. Esta última condición requiere de un alto grado de sospecha clínica y del concurso de una estrategia diagnóstica estandarizada.

Las estrategias preventivas forman una parte importante del manejo de estos pacientes e incluyen quimioprofilaxis de PBE en casos seleccionados y la aplicación de vacunas para prevenir infecciones neumocóccicas, FLU o sobreinfecciones virales por VHB o VHA en huéspedes susceptibles. 


\section{Resumen}

Las infecciones en pacientes afectados por cirrosis hepática son frecuentes, recurrentes y de pronóstico desfavorable. Su génesis está facilitada por defectos adquiridos y progresivos de la inmunidad innata y del sistema retículo-endotelial, siendo agravados por el consumo de alcohol. Estas infecciones son habitualmente bacterianas o virales y tienen habitualmente una presentación clínica estereotipada, aunque en ocasiones el diagnóstico puede ser difícil. Las neumonías, infecciones del tracto urinario, bacteriemias y peritonitis bacteriana espontánea (PBE) abarcan más del 90\% de los casos; esta última exige de una alta sospecha clínica y de un protocolo de diagnóstico estandarizado. Las medidas preventivas son importantes en el manejo de estos pacientes e incluyen quimioprofilaxis contra la PBE en casos seleccionados, vacunas contra infecciones neumocóccicas e influenza en general, y hepatitis A y B en pacientes susceptibles. Debido a que la seroconversión con estas vacunas es deficiente, la inmunización activa debiera ser aplicada tan precozmente como sea posible, antes que se establezca un deterioro clínico.

\section{Bibliografía}

1.- Fierer J, Finley F. Deficient bactericidal activity against Escherichia coli in patients with cirrhosis of the liver. J Clin Invest 1979; 63: 912-21.

2.- Wyke R J, Naghovic J A, Eddleston A L W F, Williams R. Defective opsonisation and complement deficiency in serum from patients with fulminant hepatic failure. Gut 1980; 21: 643-9.

3.- Wyke R J, Rajkovic I A, Williams R. Impaired opsonization by serum from patients with chronic liver disease. Clin Exp Immunol 1983; 51: 91-8.

4.- Runyon B A. Patients with deficient ascitic fluid opsonic activity are predisposed to spontaneous bacterial peritonitis. Hepatology 1988; 8: 632-5.

5.- Andreu M, Sola R, Sitges-Serra A, Alia C, Gallen M, Vila C, et al. Risk factors for spontaneous bacterial peritonitis in cirrhotic patients with ascites. Gastroenterology 1993; 104: 1133-8.

6.- Homann C, Varning K, Hagasen K, Mollnes T E, Graudal N, Thomsen AC, et al. Acquired C3 deficiency in alcoholic cirrhosis predispose to infection and increased mortality. Gut 1997; 40: 544-9.

7.- Rajhovic J A, Williams R. Abnormalities of neutrophil phagocytosis, intracellular killing, and metabolic activity in alcoholic cirrhosis and hepatitis. Hepatology 1986; 6: 252-62.

8.- Fiuza C, Salcedo M, Clemente G, Tellado J M. In vivo neutrophil dysfunction in cirrhotic patients with advanced liver disease. J Infect Dis 2000; 182: 526-33.

9.- Rimola A, Soto R, Bory T, Arroyo V, Piera C, Rodes J. Reticuloendothelial system phagocytic activity in cirrhosis and its relation to bacterial infections and prognosis. Hepatology 1984; 4: 53-8.

10.- Eisen D P, Minchinton R M. Impact of mannosebinding lectin on susceptibility to infectious diseases. Clin Infect Dis 2003; 37: 1496-505.

11.- Yuen M F, Lau C S, Lau Y L, Wong W M, Cheng C
C, Lai C L. Mannose binding lectin gene mutations are associated with progression of liver diseases in chronic hepatitis B infection. Hepatology 1999; 29: 1248-51.

12.- Kakkanaiah V N, Shen G Q, Ojo-Amaize E A, Peter J B. Association of low concentrations of serum mannose-binding protein with recurrent infections in adults. Clin Diagn Lab Immunol 1998; 5: 319-21.

13.- Sasaki K, Tsutsumi A, Wakamiya N, Ohtani K, Watanabe Y, Nakayama N, et al. Mannose-binding lectin polymorphisms in patients with hepatitis $\mathrm{C}$ virus infection. Scand J Gastroenterol 2000; 35: 960-9.

14.- Hakozaki Y, Yoshiba M, Sekiyama K, Seike E, Iwamoto J, Mitani K, et al. Mannose-binding lectin and the prognosis of fulminant hepatic failure caused by HBV infection. Liver 2002; 22: 29-34.

15.- MacGregor R R. Alcohol and immune defense. JAMA 1986; 256: 1474-9.

16.- Rosa H, Silveiro A O, Perini R F, Arruda C B. Bacterial infections in cirrhotic patients and its relationship with alcohol. Am J Gastroenterol 2000; 95: 1290-3.

17.- Johnson D H, Cunha B A. Infections in cirrhosis. Infect Dis Clin North Am 2001; 15: 363-71.

18.- Toledo C, Flores C, Saenz M, Jiménez P, Tejero A, Ibarra $\mathrm{H}$, et al. Infecciones bacterianas en la cirrosis hepática. Rev Méd Chile 1994; 122: 788-94.

19.- Chesta J, Brahm J, Poniachik J, Latorre R, Hurtado C, Novoa $\mathrm{X}$, et al. Peritonitis bacteriana espontánea: una complicación frecuente y recurrente en pacientes cirróticos con ascitis. Rev Méd Chile 1991; 119: 273-8.

20.- Rimola A, García-Tsao G, Navasa M, Piddock L, Planas R, Bernard B, et al. Diagnosis, treatment and prophylaxis of spontaneous bacterial peritonitis: a consensus document. J Hepatol 2000; 32: 142-53.

21.- Nolla-Salas J, Almela M, Gasser I, Latorre C, Salvado M, Coll P. Spontaneous Listeria monocytogenes peritonitis: a population-based study of 13 cases collected in Spain. Am J Gastroenterol 2002; 97: $1507-$ 11.

22.- Jayaraj K, Di Bisceglie A M, Gibson S. Spontaneous bacterial peritonitis caused by infection with Listeria monocytogenes: a case report and review of the literature. Am J Gastroenterol 1998; 93: 1556-8.

23.- Fernández J, Navasa M, Gómez J, Colmenero J, Vila J, Arroyo V, et al. Bacterial infections in cirrhosis: Epidemiological changes with invasive procedures and norfloxacin prophylaxis. Hepatology 2002; 35: 140-8.

24.- Burroughs A K, Rosenstein I J, Epstein O, HamiltonMiller J M T, Brumfitt W, Sherlock S. Bacteriuria and primary biliary cirrhosis. Gut 1984; 25: 133-7.

25.- Gransden W R, Eykyn S J, Phillips I. Pneumococcal bacteraemia: 325 episodes diagnosed at St Thomas's Hospital. Br Med J 1985; 290: 505-8.

26.- Fica A, Belletti J, Cruzat C, Rojas D, Montalva M. Tuberculosis intestinal: Análisis de casos clínicos y autopsias. Rev Méd Chile 1991; 119: 1153-9.

27.- Howard R J, Pessa M E, Brenamann B H, Ramphal R. Necrotizing soft-tissue infections caused by marine vibrios. Surgery $1985 ; 98: 126-30$.

28.- Fica A, Caorsi B, Piemonte P. Síndrome disentérico, insuficiencia renal aguda y shock séptico letal asociados a infección por Salmonella Enteritidis. Descripción de tres casos. Rev Méd Chile 1997; 125: 1055 62.

29.- Harnisch J P, Tronca H, Nolan C M, Turck M, Holmes KK. Diphtheria among alcoholic urban adults. A decade of experience in Seattle. Ann Intern Med 1989; 111: 71-82. 
30.- Drancourt M, Mainardi J L, Brouqui P, Vandenesch F, Carta A, Lehnert F, et al. Bartonella (Rochalimeae) quintana endocarditis in three homeless men. N Engl J Med 1995; 332: 419-23.

31.- Runyon B A, Canawati H N, Akriviadis E A. Optimisation of ascitic fluid culture. Gastroenterology 1988; 95: 1351-5.

32.- Runyon B A, Hoefs J C. Ascitic fluid analysis in the differentiation of spontaneous bacterial peritonitis from gastrointestinal tract perforation into ascitic fluid. Hepatology 1984; 4: 447-50.

33.- Soares-Weisser K, Brezis M, Leibovici L. Antibiotics for spontaneous bacterial peritonitis in cirrhotics (Cochrane Review). In: The Cochrane Library, Issue 3, 2003. Oxford: Udpate Software.

34.- McCashland T M, Preheim L C, Gentry-Nielsen M J. Pneumococcal vaccine response in cirrhosis and liver transplantation. J Infect Dis 2000; 181: 757-60.

35.- Pirovino M, Lydick E, Grob P J, Arrenbrecht S, Altorfer J, Scmid M. Pneumococcal vaccination: the response of patients with alcoholic liver cirrhosis. Hepatology 1984; 4: 946-9.

36.- Simberkoff M S, Schifman G S, Spicehandler J R, Moldover N H, Rahal J J Jr. Radioimmunoassay and opsonic antibody responses to pneumococcal capsular polysaccharide vaccine in serum and ascitic fluid of cirrhotic patients. J Clin Microbiol 1983; 18: 154-9.

37.- Artz A S, Ershler W B, Longo D L. Pneumococcal vaccination and revaccination of older adults. Clin Microbiol Rev 2003; 16: 308-18.

38.- Duchini A, Viernes E, Nyberg L M, Hendry M, Pockros P J. Hepatic decompensation in patients with cirrhosis during infection with influenza. Arch Intern Med 2000; 160: $113-5$

39.- Duchini A, Hendry R M, Redfield D C, Pockros P J. Influenza infection in patients before and after liver transplantation. Liver Transplant 2000; 6: 531-42.

40.- Gaeta G B, Stornaiuolo G, Precone D F, Amendola A, Zanetti AR. Immunogenicity and safety of an adjuvanted influenza vaccine in patients with decompensated cirrhosis. Vaccine 2002; 20 Suppl 5: B33B35.

41.- Keefe E B. Is hepatitis A more severe in patients with chronic hepatitis B and other chronic liver diseases? Am J Gastroenterol 1995; 90: 201-5.

42.- Dumot J A, Barnes D S, Younossi Z, Gordon S M, Avery R K, Domen R E, et al. Immunogenicity of hepatitis A vaccine in decompensated liver disease. Am J Gastroenterol 1999; 94: 1601-4.

43.- Riedemann S, Ibarra H, Reinhardt G, Frosner G, Safary A. Prevalencia de anticuerpos contra la hepatitis A en niños en edad escolar. Rev Méd Chile 1998 126: 1161-4.

44.- Arguedas M R, Johnson A, Eloubeidi M A, Fallon M B. Immunogenicity of hepatitis A vaccination in decompensated cirrhotic patients. Hepatology 2001; 34: 28-31.

45.- Keefe E B, Iwarson S, McMahon B J, Lindsay K L, Koff R S, Manns M, et al. Safety and immunogenicity of hepatitis A vaccine inpatients with chronic liver disease. Hepatology 1998; 27: 881-6.

46.- Lee S D, Chan C Y, Yu M I, Lu R H, Chang F Y, Lo $\mathrm{K}$ J. Hepatitis B vaccination in patients with chronic hepatitis C. J Med Virol 1999; 59: 463-8.

47.- Horlander J C, Boyle N, Manam R, Schenk M, Herring $\mathrm{S}$, Kwo P Y, et al. Vaccination against hepatitis B in patients with chronic liver disease awaiting liver transplantation. Am J Med Sci 1999; 318: 304-7.

48.- Arguedas M R, McGuire B M, Fallon M B. Implementation of vaccination in patients with cirrhosis. Dig Dis Sci 2002; 47: 384-7.

49.- Bernard B, Grange J D, Khac E N, Amiot X, Opolon $\mathrm{P}$, Poynard T. Antibiotic prophylaxis for the prevention of bacterial infections in cirrhotic patients with gastrointestinal bleeding: a meta-analysis. Hepatology 1999; 29: 1655-61.

50.- Gines P, Rimola A, Planas R, Vargas V, Marco F, Almela $\mathrm{M}$, et al. Norfloxacin prevents spontaneous bacterial peritonitis recurrence in cirrhosis: results of a double-blind, placebo-controlled trial. Hepatology 1990; 12 (4 Pt 1): 716-24.

51.- Singh N, Gayowski T, Yu V L, Wagener M M. Trimethoprim-sulfamethoxazol for the prevention of spontaneous bacterial peritonitis in cirrhosis: a randomized trial. Ann Intern Med 1995; 122: 5958 .

52.- Soares-Weisser K, Brezis M, Tur-Kaspa R, Leibovici L. Antibiotic prophylaxis for cirrhotic patients with gastrointestinal bleeding. (Cochrane Review). In: The Cochrane Library, Issue 3, 2003. Oxford: Udpate Software.

53.- Runyon B A, Antillon M R, Montano A A. Effect of diuresis versus therapeutic paracentesis on ascitic fluid opsonic activity and serum complement. Gastroenterology 1989; 97: 158-62.

Correspondencia a:

Alberto Fica Cubillos

afica@ns.hospital.uchile.cl 